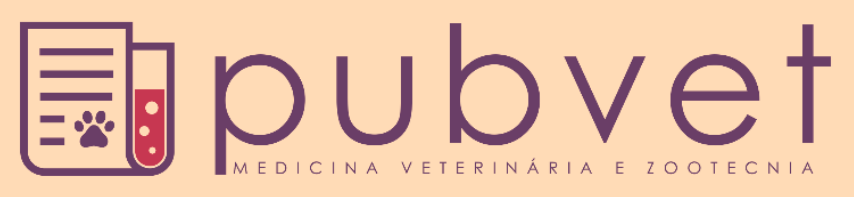

https://doi.org/10.31533/pubvet.v14n1a489.1-4

\title{
Incidência de hemoparasitoses em cães da região sul da cidade de Palmas, Tocantins
}

\author{
Aristóteles Gomes Caponi $^{1 *} \bullet$, Luís Flávio Silva Botelho ${ }^{2}$, Kedma Nayra da Silva Marinho ${ }^{3} \bullet$, \\ Annanda Karen de Sousa $^{1 \bullet}$, Brenda Yasmin Aguiar de Carvalho ${ }^{1}{ }^{\circ}$, Maria Eduarda Alves Bonfim ${ }^{10}$ \\ ${ }^{I}$ Acadêmico(a) do curso de Medicina Veterinária do Centro Universitário Católica do Tocantins, Campus II, Palmas-TO; \\ ${ }^{2}$ M.V.; M.Sc.; Centro Universitário Católica do Tocantins, Brasil. \\ ${ }^{3}$ Zootecnista; M.Sc.; Centro Universitário Católica do Tocantins, Brasil. \\ *Autor para correspondência, E-mail: lfsbotelho@hotmail.com
}

Resumo. O presente estudo foi realizado por meio de questionário online com moradores da região sul de Palmas-TO. Buscou identificar a incidência de hemoparasitoses em cães e o nível de conhecimento dos participantes acerca das enfermidades. Ficou demonstrado que a maioria dos respondentes - jovens entre 18 e 25 anos (80,58\%) com ensino médio completo $(55,34 \%)$ e usuários frequentes de redes sociais - conhecem as doenças pesquisadas a partir do termo popular, "doenças do carrapato" $(56,31 \%)$, e não de sua nomenclatura técnica, ou seja, hemoparasitoses $(31,07 \%)$. O estudo teórico revelou que a erliquiose $(9,71 \%)$ é prevalente em cães de área urbana, devido à maior ocorrência do parasita Rhipicephalus sanguineus nessas regiões.

Palavras-chave: células sanguíneas, ectoparasitas, doenças

\section{Incidence of hemoparasitosis in dogs from the southern region of Palmas, Tocantins}

\begin{abstract}
This study was conducted through an online questionnaire with residents of the southern region of Palmas-TO. It sought to identify the incidence of hemoparasitosis in dogs and the participants' level of knowledge about the diseases. It was shown that the majority of respondents - young people between 18 and 25 years old $(80.58 \%)$ with complete high school (55.34\%) and frequent users of social networks - know the diseases researched from the popular term, "diseases of the tick "(56.31\%), and not its technical nomenclature, ie hemoparasitic diseases $(31.07 \%)$. The theoretical study revealed that erliquiosis $(9.71 \%)$ is prevalent in dogs of urban area, due to the higher occurrence of the parasite Rhipicephalus sanguineus in these regions.
\end{abstract}

Keywords: blood cells, ectoparasites, diseases

\section{Incidencia de hemoparasitosis en perros de la región sur de Palmas, Tocantins}

Resumen. Este estudio se realizó a través de un cuestionario en línea con residentes de la región sur de Palmas-TO. Se buscó identificar la incidencia de hemoparasitosis en perros y el nivel de conocimiento de los participantes sobre las enfermedades. Se demostró que la mayoría de los encuestados (jóvenes entre 18 y 25 años de edad (80.58\%) con educación secundaria completa $(55.4 \%)$ y usuarios frecuentes de redes sociales) conocen las enfermedades investigadas del término popular, "enfermedades de la garrapata" (56,31\%), y no su nomenclatura técnica, es decir, enfermedades hemoparasitarias $(31,07 \%)$. El 
estudio teórico reveló que la erliquiosis $(9,71 \%)$ prevalece en los perros del área urbana, debido a la mayor incidencia del parásito Rhipicephalus sanguineus en estas regiones.

Palabras-clave: células sanguíneas, ectoparásitos, enfermedades

\section{Introdução}

As hemoparasitoses caninas são doenças causadas por microrganismos patogênicos que parasitam as células sanguíneas do cão (Costa, 2011; Mundim et al., 2008). As principais, nessa espécie, são a babesiose, causadas pelos protozoários Babesia canis vogeli (Silva et al., 2012), a erliquiose, causada pela bactéria Ehrlichia canis (Aguiar et al., 2007), e a anaplasmose, causada pela bactéria Anaplasma platys (Boozer \& Macintire, 2003; Rikihisa, 2000).

A transmissão se dá pela picada de carrapatos, principalmente o Rhipicephalus sanguineus (Baneth et al., 2001; Groves et al., 1975). Observa-se uma maior manifestação regular de patologias transmitidas por carrapatos em regiões consideradas peri-urbanas, onde os cães encontram-se vulneráveis àqueles (Cordovés, 1997; Godoi \& Silva, 2009; Groves et al., 1975; Moreira, 2001). Essas enfermidades são consideradas endêmicas no país e presentes em todo o território brasileiro (Machado, 2004; Silva et al., 2013).

Os sinais clínicos e alterações laboratoriais mais comuns para erliquiose e anaplasmose são anemia, trombocitopenia, perda total de apetite (anorexia), palidez de mucosas, linfoadenomegalia, leucopenia, letargia etc; enquanto na babesiose tem-se anemia hemolítica, letargia, hipertermia, esplenomegalia, icterícia, perda de peso, desidratação etc (Harrus et al., 2002; Megid et al., 2016; Shipov et al., 2008).

O diagnóstico é baseado na rígida avaliação dos sinais clínicos, realização de exames hematológicos (hemograma e esfregaços sanguíneos) e bioquímicos, além de métodos sorológicos (Waner et al., 2001).

Como medidas profiláticas é ideal que se realize o controle do ectoparasita $R$. sanguineus, tanto no ambiente realizando a pulverização com substâncias que tenham em sua composição cipermetrina ou amitraz, quanto no animal, fazendo a utilização de carrapaticidas. É recomendada a quarentena de animais recém-chegados em canis (Megid et al., 2016).

O presente trabalho teve como objetivo demonstrar a prevalência das principais hemoparasitoses em cães localizados na região sul da cidade, e determinar o nível de conhecimento da população a respeito dessas doenças.

\section{Material e Métodos}

O estudo conduziu-se no período de trinta dias, sendo iniciado em 28 de março de 2019 e concluído em 28 de abril de 2019. Foi criado um formulário online na plataforma do Google ${ }^{\odot}$, denominada Google Forms, que possibilitou uma interação digital e dinâmica por meio de questões com os usuários, que acessaram ao link disponibilizado em redes sociais, participando voluntariamente do trabalho.

As perguntas realizadas apresentavam uma linha baseada em quantificação e qualificação das hemoparasitoses (doenças do carrapato) em cães localizados na região sul da cidade de Palmas, Tocantins. O questionário continha as seguintes interrogações e respostas: se o indivíduo residia na região proposta para o estudo (sim ou não); qual a idade (18 a 25 anos; 26 a 40 anos; 41 a 60 anos; mais de 60 anos); sexo (masculino; feminino; outro); grau de escolaridade (ensino médio completo; ensino superior completo; mestrado, doutorado e/ou pós-doutorado; outro); idade do animal (0 a 11 meses; 1 a 5 anos; 6 a 9 anos; mais de 9 anos); sexo do animal (macho ou fêmea); quantidade de animais na residência (apenas 1; 2 a 4 animais; mais de 4 animais); se o internauta possuía conhecimento sobre as hemoparasitoses (sim; não; um pouco); se possuía conhecimento sobre as "doenças do carrapato" (babesiose, erliquiose e anaplasmose) (sim; não; um pouco); se o animal já havia apresentado ou apresentava alguma das enfermidades (babesiose; erliquiose; anaplasmose; sim, mas não recordava qual; não, nenhuma); se conhecia o tratamento para alguma das afecções (babesiose; erliquiose; anaplasmose; não conhecia); e se o animal já havia sido tratado contra alguma das patologias (babesiose; erliquiose; anaplasmose; sim, mas não recordava qual; não, sem realização de tratamento). 


\section{Resultados e discussão}

Foram obtidas 103 (cento e três) respostas. As maiores porcentagens obtidas para as diferentes variáveis em estudo, ou seja, participantes, animais e doenças, estão expostos na Tabela 1.

Tabela 1. Maiores porcentagens (\%) obtidas para fatores relacionados às três variáveis em estudo

\begin{tabular}{|c|c|c|c|c|c|c|c|}
\hline \multicolumn{2}{|l|}{ Participantes } & \multicolumn{2}{|c|}{ Animais } & \multicolumn{4}{|c|}{ Doenças } \\
\hline $\begin{array}{l}\text { Idade de } 18- \\
25 \text { anos }\end{array}$ & $\begin{array}{c}\text { Ensino } \\
\text { Médio } \\
\text { Completo }\end{array}$ & $\begin{array}{c}\text { Idade De } 1 \\
\text { A } 5 \text { Anos }\end{array}$ & Fêmea & $\begin{array}{c}\text { Conhecimento } \\
\text { sobre } \\
\text { Hemoparasitose }\end{array}$ & $\begin{array}{l}\text { Conhecimento sobre } \\
\text { "Doenças do Carrapato" }\end{array}$ & $\begin{array}{c}\text { Incidência De } \\
\text { Erliquiose }\end{array}$ & $\begin{array}{l}\text { Desconhecimento } \\
\text { Tratamentos }\end{array}$ \\
\hline 80,58 & 55,34 & 58,25 & 51,46 & 31,07 & 56,31 & 9,71 & 40,78 \\
\hline
\end{tabular}

Com os resultados obtidos, é possível sugerir que os respondentes mais jovens, com idade entre 18 a 25 anos $(80,6 \%)$, representaram a maior quantidade de internautas. Isso pode estar relacionado à maior facilidade de acesso e interesse na utilização das plataformas digitais, além de estar interligado com o quesito grau de escolaridade, pois devido às respostas serem mais voltadas para a opção de ensino médio completo $(55,4 \%)$. Nota-se, que realmente o público tende a ser composto por uma geração mais nova, o que pode influenciar diretamente nos dados gerados pela pesquisa. Esse fator, por exemplo, pode ter influência no nível de conhecimento da população a respeito das doenças, onde os mais jovens provavelmente possuem mais contato com informações e acompanhamento a respeito delas, como observado nos resultados. Entretanto, o termo utilizado é relevante, visto que a grande maioria dos participantes desconhece o termo técnico "hemoparasitose" (31,1\%), tendo mais noção da nomenclatura popular: "doença do carrapato" $(56,3 \%)$.

Quanto à idade dos animais, os de 1 a 5 anos foram os mais selecionados (58,3\%), sendo semelhante ao descrito por Moreira (2001); sugerindo que para erliquiose, por exemplo, o início da idade reprodutiva predispõe à patologia. Concordante a essa análise, as fêmeas do presente estudo, de acordo com o questionário, estavam em maior quantidade $(51,5 \%)$, podendo ocorrer pelo fato das mesmas terem mais contato com ambiente hospitalar para realização de castrações, além da maior incidência de distúrbios obstétricos, que pode levar a maior identificação das afecções estudadas. Em relação às três doenças do carrapato, a erliquiose foi a mais relatada $(9,7 \%)$ pelos participantes do estudo. Dados semelhantes aos resultados apontados por Salgado (2006); onde é sugestivo que isso ocorra devido à procedência dos animais serem de área urbana onde há a maior incidência do carrapato Rhipicephalus sanguineus, principal vetor dessa afecção. Salgado (2006) também apontou que a queda na imunidade do animal facilita o aparecimento deste hemoparasita, explicando o aumento da frequência da afecção nos animais em relação às outras hemoparasitoses.

No que diz respeito ao tratamento para essas doenças, percebeu-se que a maioria dos respondentes sinalizou desconhecer o tratamento para as afecções mencionadas $(40,8 \%)$, o que indica, segundo Silva et al. (2014), a necessidade de realização de campanhas educativas de orientação aos proprietários, bem como a prática de avaliações médicas veterinárias completas, acompanhadas de tratamento.

\section{Conclusões}

O estudo realizado evidenciou aspectos importantes a respeito da doença erliquiose, revelando que esta, apresenta maior incidência em cães de área urbana, devido à ocorrência do parasita Rhipicephalus sanguineus nesse tipo de ambiente. Foi possível perceber também que a maioria dos partícipes desconhece a nomenclatura técnica das doenças pesquisadas, tendo mais contato com o nome popular das doenças, ou seja, "doenças do carrapato", o que sinaliza para a necessidade de realização de mais campanhas educativas a respeito das referidas doenças, no caso as hemoparasitoses.

\section{Referências bibliográficas}

Aguiar, D. M., Cavalcante, G. T., Pinter, A., Gennari, S. M., Camargo, L. M. A. \& Labruna, M. B. (2007). Prevalence of Ehrlichia canis (Rickettsiales: Anaplasmataceae) in dogs and Rhipicephalus sanguineus (Acari: Ixodidae) ticks from Brazil. Journal of Medical Entomology, 44(1):126-132. 
Baneth, G. A. D., Samish, M., Alekseev, E., Aroch, I. \& Shkap, V. (2001). Transmission of Hepatozoon canis to dogs by naturally-fed or percutaneously-injected Rhipicephalus sanguineus ticks. Journal of Parasitology, 87(3):606-612.

Boozer, A. L. \& Macintire, D. K. (2003). Canine babesiosis. The Veterinary Clinics of North America. Small Animal Practice, 33(4):885-904.

Cordovés, C. O. (1997). Carrapato: controle ou erradicação (Vol. 1). Porto Alegre, Rio Grande do Sul: Guaíba Agropecuária.

Costa, H. X. (2011). Interação de hemoparasitos e hemoparasitoses em casos clínicos de trombocitopenia em cães no município de Goiânia. Masster of Science, Universidade Federal do Goiás, Goiânia, Goiás, Brasil.

Godoi, C. R. \& Silva, E. F. P. (2009). Carrapato Boophilus microplus e impacto na produção animalRevisão de literatura. PUBVET, 3(22):Art 606.

Groves, M. G., Dennis, G. L., Amyx, H. L. \& Huxsoll, D. L. (1975). Transmission of Ehrlichia canis to dogs by ticks (Rhipicephalus sanguineus). American Journal of Veterinary Research, 36(7):937-940.

Harrus, S., Alleman, A. R., Bark, H., Mahan, S. M. \& Waner, T. (2002). Comparison of three enzymelinked immunosorbant assays with the indirect immunofluorescent antibody test for the diagnosis of canine infection with Ehrlichia canis. Veterinary Microbiology, 86(4):361-368.

Machado, R. Z. (2004). Erliquiose canina. Revista Brasileira de Parasitologia Veterinária, 1353-57.

Megid, J., Ribeiro, M. G. \& Paes, A. C. (2016). Doenças infecciosas em animais de produção e de companhia. Rio de Janeeiro, Brasil: Roca.

Moreira, S. M. (2001). Estudo retrospectivo (1998-2001) da erliquiose canina em Belo Horizonte:: avaliação clínica e laboratorial de infecções experimentais. Arquivo Brasileiro de Medicina Veterinária e Zootecnia, 55(2):1-6.

Mundim, E. C. S., Francisco, M. M. S., Souza, J. N., Alencar, M. A. G. \& Ramalho, P. C. D. (2008). Incidência de hemoparasitoses em cães (Canis familiares) de rua capturados pelo Centro de Controle de Zoonoses (CCZ) da cidade de Anápolis-GO. Ensaios e Ciência: Ciências Biológicas, Agrárias e da Saúde, 12(2):108-114.

Rikihisa, Y. (2000). Diagnosis of emerging ehrlichial diseases of dogs, horses, and humans. Journal of Veterinary Internal Medicine, 14(3):250-251.

Salgado, F. P. (2006). Identificação de hemoparasitos e carrapatos de cães procedentes do Centro de Controle de Zoonoses de Campo Grande, Estado do Mato Grosso do Sul, Brasil. PhD, Universidade Federal do Mato Grosso, Campo Grande, Mato Grosso, Brasil.

Shipov, A., Klement, E., Reuveni-Tager, L., Waner, T. \& Harrus, S. (2008). Prognostic indicators for canine monocytic ehrlichiosis. Veterinary Parasitology, 153(1-2):131-138.

Silva, A. B., Costa, A. P., Sá, J. C., Costa, F. B., Santos, A. C. G. \& Rita, M. S. N. C. (2012). Detecção molecular de Babesia canis vogeli em cães e em Rhipicephalus sanguineus na mesorregião do oeste maranhense, nordeste brasileiro. Ciência Animal Brasileira, 13(3):388-395.

Silva, M. C. A., Mundim, A. V., Mendonça, G. A., Mundim, M. J. S. \& Guimarães, E. C. (2014). Hemoparasitos em cães domésticos naturalmente infectados, provenientes das zonas urbana e rural do município de Abadia dos Dourados, Minas Gerais, Brasil. Bioscience Journal, 30(5):892-900.

Silva, M. V. M., Fernandes, R. A., Nogueira, J. L. \& Ambrósio, C. E. (2013). Erliquiose canina: revisão de literatura. Arquivos de Ciências Veterinárias e Zoologia da UNIPAR, 14(2):139-143.

Waner, T., Harrus, S., Jongejan, F., Bark, H., Keysary, A. \& Cornelissen, A. W. C. A. (2001). Significance of serological testing for ehrlichial diseases in dogs with special emphasis on the diagnosis of canine monocytic ehrlichiosis caused by Ehrlichiacanis. Veterinary Parasitology, 95(1):1-15.

Recebido: 23 de julho, 2019.

Aprovado: 4 de setembro, 2019.

Publicado: 29 de fevereiro, 2020.

Licenciamento: Este artigo é publicado na modalidade Acesso Aberto sob a licença Creative Commons Atribuição 4.0 (CC-BY 4.0), a qual permite uso irrestrito, distribuição, reprodução em qualquer meio, desde que o autor e a fonte sejam devidamente creditados. 